\title{
A neglected organ: Spleen
}

\section{İhmal edilmiş organ: Dalak}

\author{
Mehmet Atalar ${ }^{1}$, Neslihan Köse², Büşra Şekerr ${ }^{3}$,Halil Çaylak ${ }^{4}$, Enes Güil ${ }^{1}$
}

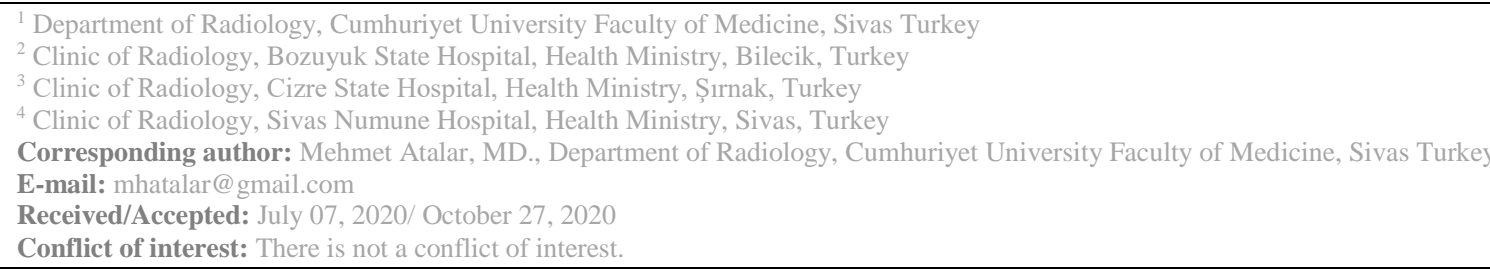

\section{SUMMARY}

The spleen is an important organ of reticuloendothelial system, but it is a less well-known organ in terms of its pathologies. Therefore, the spleen is considered a 'forgotten or neglected organ' by radiologists and clinicians. Spleen pathologies show a wide spectrum ranging from congenital anomalies to malignant lesions. Radiological imaging methods play an important role in detecting these pathologies.

Keywords: Spleen, radiology, computed tomography, magnetic resonance imaging, ultrasound

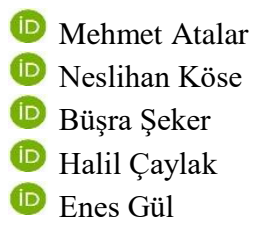

ORCID IDs of the authors:

M.A. 0000-0003-3076-8072

N.K. 0000-0002-3741-5133

B.Ş. 0000-0001-7766-4276

H.Ç. 0000-0001-8089-4822

E.G. 0000-0002-5562-2697

\section{ÖZET}

Dalak, retiküloendotelyal sistemin önemli bir organı olmakla birlikte patolojileri daha az bilinmektedir. Bu nedenle dalak, klinisyenler ve radyologlar tarafından "unutulmuş veya ihmal edilmiş organ" olarak kabul edilmektedir. Dalak patolojileri, konjenital anomalilerden malign lezyonlara değişen bir aralık göstermektedir. Radyolojik görüntüleme yöntemleri. bu patolojilerin tespitinde önemli rol oynamaktadır.

Anahtar sözcükler: Dalak, radyoloji, bilgisayarlı tomografi, manyetik rezonans görüntüleme, ultrasonografi

\section{INTRODUCTION}

The spleen is an organ of the hematological system and plays a role in immune response, red blood cell storage and hematopoiesis. Most splenic lesions are detected incidentally. The spleen is considered 'the neglected organ' among radiologists and clinicians, although it is well visualized on abdominal radiological imaging. Ultrasound (US) and computed tomography (CT) are the most frequently used modalities in the detection of splenic lesions. Magnetic resonance imaging (MRI) is generally used as a supporting modality. ${ }^{1,2}$ In this pictorial article, we aimed to present common and rare lesions related to the spleen in the light of imaging findings (including US, CT, and MRI). We classified the lesions affecting the spleen in six main categories: (a) Normal variants, (b) congenital diseases, (c) trauma, (d) infectious / inflammatory diseases, (e) vascular and hematological disorders, (f) benign and malignant tumors, and (g) other diseases. All cases confirmed by surgical resection, or radiological follow-up study.

\section{NORMAL VARIANTS}

\section{Zebra spleen}

Zebra spleen indicates temporary heterogeneous parenchymal enhancement of the spleen during 
arterial or early portal venous phases of contrast enhancement in CT, MRI, or ultrasound imaging. This appearance is due to the variable blood flow rates between the early-contrasted red pulp and later-contrasted white pulp (Figure 1). The heterogeneous enhancement in the spleen is important as it can mimic a splenic trauma, and infarction. ${ }^{1}$

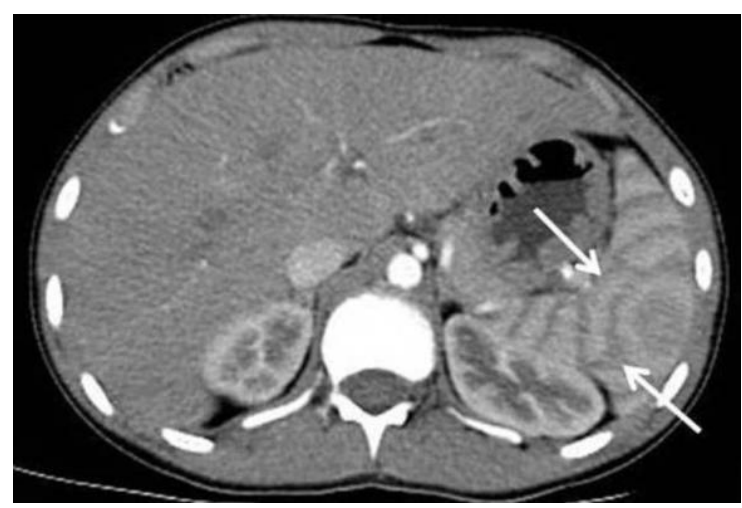

Figure 1: Zebra spleen pattern in twenty-one-year-old woman. The arterial phase CT image reveals the archiform pattern of enhancement.

\section{Splenic clefts, notches and lobulations}

The fetal spleen appears to be lobular, but the lobulation disappears by birth. Lobulation of the spleen may persist after fetal life and results as a variation in normal shape (Figure 2). They are typically seen along the medial part of the spleen and are sometimes supplied by a branch of the splenic artery. ${ }^{2}$ When it is closely related to the kidney, it should not be misinterpreted as a kidney- derived mass. The notches and clefts are usually located on the diaphragmatic surface of the spleen and represent remnants of the grooves that seperated the fetal lobules (Figure 3 ). These clefts are sometimes as deep as $2-3 \mathrm{~cm}$ and can cause misinterpretations such as laceration of the spleen. Absence of free abdominal fluid and persistence of this appearance on delayed images are useful differentiating clefts from laceration. ${ }^{3}$

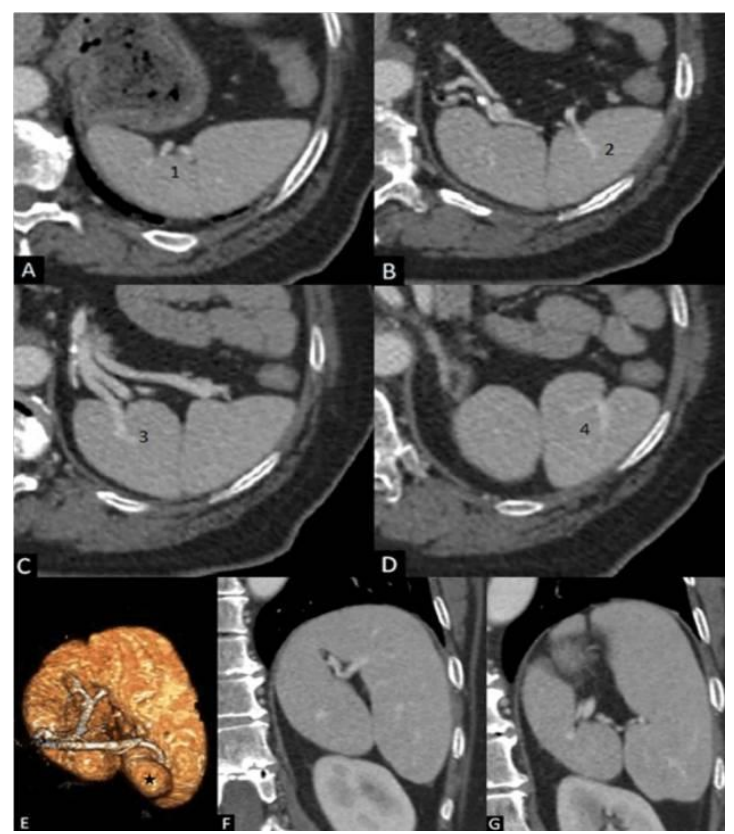

Figure 2: Splenic lobulation. (A, B, C, D) Axial contrast-enhanced CT and (E, F) shows lobulations with a deep fissure and four hila $(1-4)$. (E) Coronal 3D image shows lobulation, multiple hila and a focal bulge in the contour of the inferior aspect of the spleen (black star). 


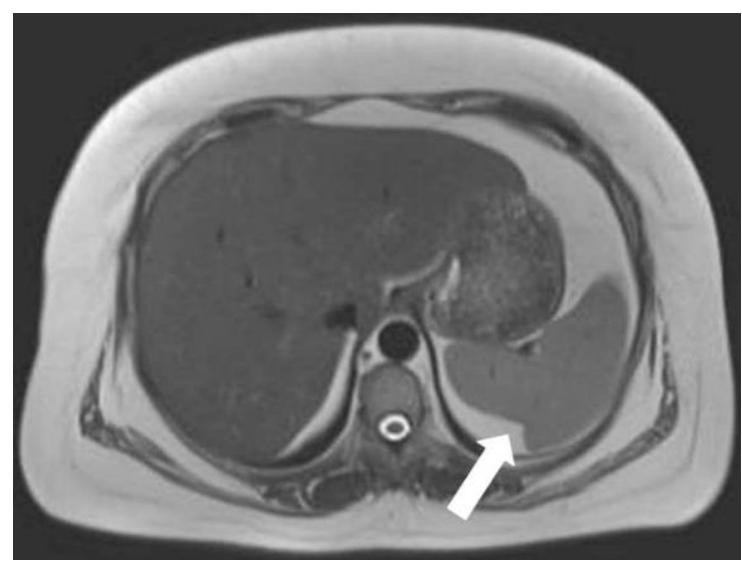

Figure 3: Splenic cleft. Axial T2W MR image shows 1-cm-deep cleft on the medial aspect of the spleen (arrow).

\section{CONGENITAL DISEASES}

\section{Splenic duplication}

Splenic duplication can be included in the category of anomaly with splenosis. It is rarely described in the literature as case reports. Splenic duplication can be included in the category of abnormality with splenosis, as this abnormality consists of several abnormal components, any of which are not always present. Splenic duplication imaging findings were first reported by Kim et al. It is diagnostic to see two separate spleens with their own veins, especially in cross-sectional imaging methods. Enlarged splenic volume in splenic duplication can lead to increased blood flow, and venous drainage (Figure 4). ${ }^{4}$

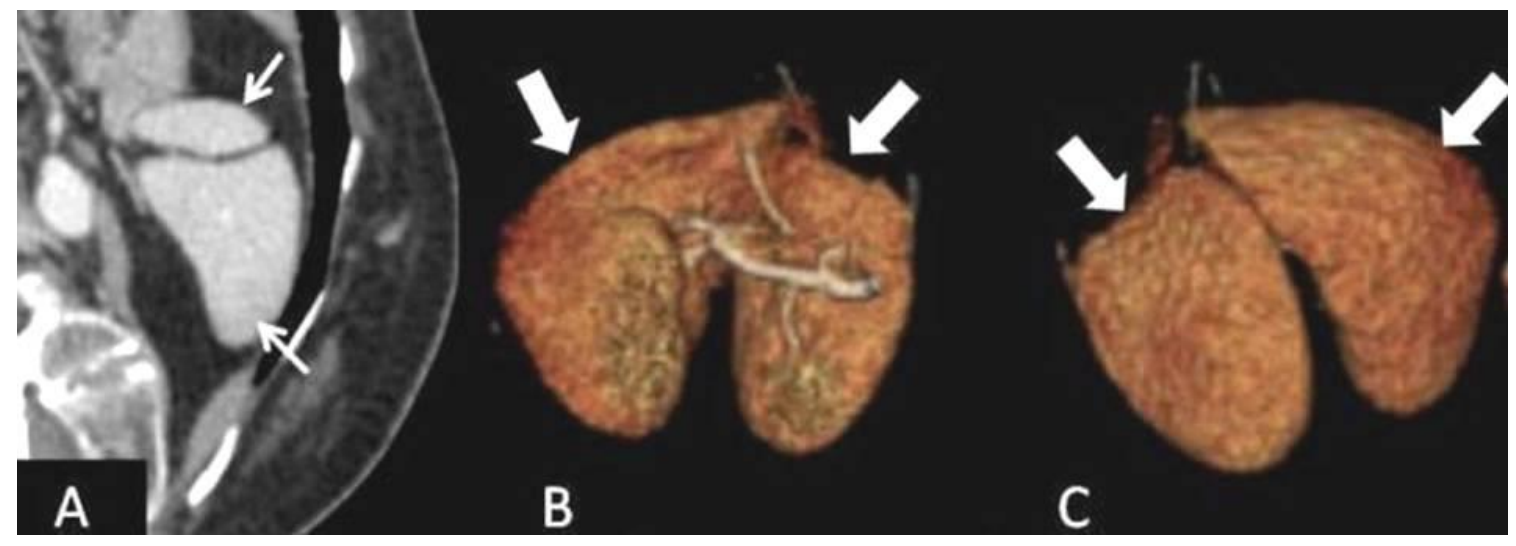

Figure 4: Sixty-five-year-old woman with splenic duplication. (A) Axial contrast-enhanced computed tomography, and $(\mathrm{B}, \mathrm{C})$ three-dimensional volume rendered images demonstrate two spleens being located adjacent to each other (arrows).

\section{Accessory spleen}

Accessory spleen is the most common congenital anomaly of the spleen. It can be solitary or multifocal. It is usually located near the splenic hilum (75\%) and the tail of the pancreas (25\%) [2]. However it can ocur anywhere in the peritoneal cavity. Diagnosing an accessory spleen in the tail of pancreas may be a challenge, because some pancreatic tumors can share similar imaging characteristics with intrapancreatic accessory spleen..$^{5}$ Accessory spleen is appear as a round or ovoid mass with well-defined borders measures from a few milimeters to centimeters. On all imaging modalities, it shows similar imaging characteristics as a normal spleen (Figure 5). Reporting it is important in a patient with a hematologic or autoimmune disorder, as they may be responsible for disease recurrence after splenectomy. ${ }^{6}$ 


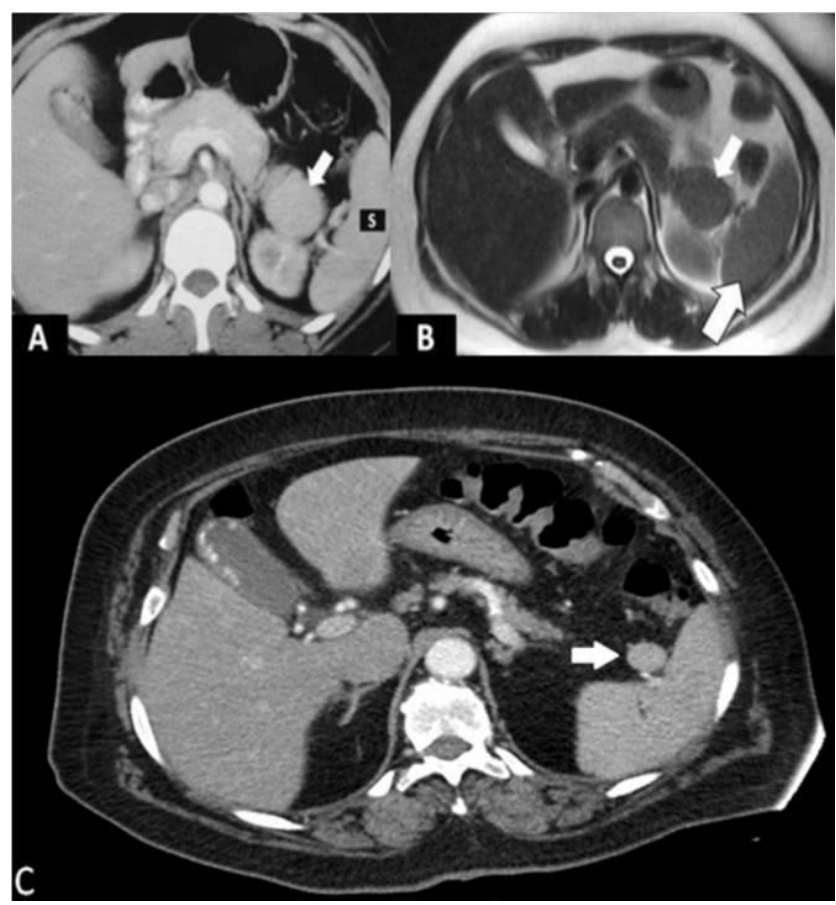

Figure 5: Thirty-two-year-old man with intrapancreatic accessory spleen. (A) Axial contrast-enhanced computed tomography, and (B) axial T2W MR images demonstrate a focal bulge in the contour of the tail of the pancreas (A, B; white arrow). It is similar to that of the adjacent spleen (A; S, B; large white arrow). (C) 74-year-old woman with accessory spleen. Axial contrast-enhanced CT demonstrate an accessory spleen in its most common location, at the splenic hilum. It has the same density as spleen.

\section{Splenopancreatic Fusion}

Splenopancreatic fusion which is a form of splenopancreatic field anomalies may result from disturbances in the embryogenesis, as the two organs arise from dorsal mesogastrium near each other. ${ }^{3}$ Splenopancreatic fusion is a rare anomaly mainly associated with trisomy 13.
Splenopancreatic fusion is often asymptomatic, but Its diagnosis is important in patients scheduled to prevent possible intraoperative or postoperative complications such as bleeding or pancreatic ductal leak. ${ }^{7}$ In radiological imaging, it is important to show the parenchymal continuities of the pancreatic tail and spleen hilum (Figure 6).

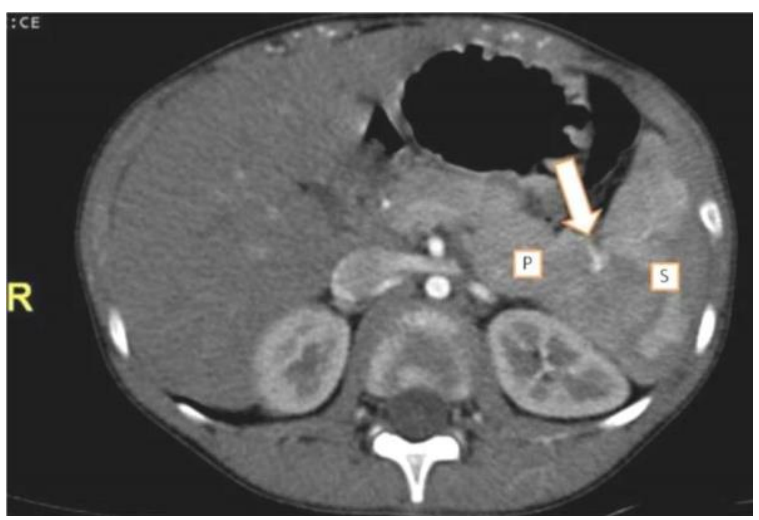

Figure 6: Eight-year-old boy with splenopancreatic fusion. Axial contrast-enhanced abdominal CT shows the pancreatic tail in continuity (arrow) with the spleen (P; pancreas, S; spleen).

\section{Asplenia and Polysplenia Syndrome}

Asplenia is characterized by the complete absence of the spleen and the ambigus position of the abdominal organs. There are a wide variety of anomalies, including congenital heart diseases, eparterial bronchi, trilob lungs, bilateral right atrium, midline liver, and intestinal malrotation. It has a very high mortality rate of up to $95 \%$ of 
patients in the first year of life because of related congenital heart disease. ${ }^{2}$ Polysplenia is associated with multiple highly variable cardiovascular and visceral anomalies (Figure 7). Multiple and separate spleens are seen on the left or right side of the upper quadrant and always on the same side as the stomach Other anomalies are right-sided stomach, midline or left-sided liver, intestinal malrotation, short pancreas, absence of gallbladder, inferior vena cava anomalies, hyparterial bronchi and bilobed lungs. Most patients die by the age of 5 years, yet 5 to $10 \%$ of the patients reach adulthood due to a normal heart or minor cardiac defects. $^{2}$

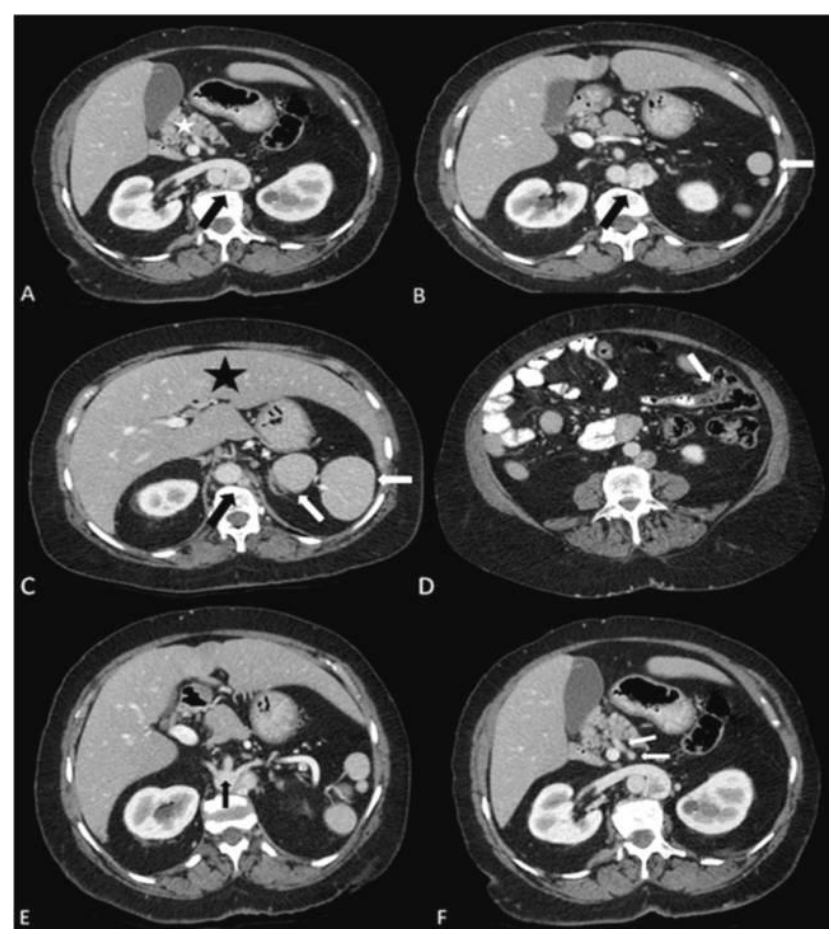

Figure 7: Incidentally detected polysplenia syndrome in 67-year-old woman. Axial contrast enhanced CT shows multiple round spleens (B, C; white arrows) in different sizes in the left upper quadrant. Liver is in the midline ( $\mathrm{C}$; black star). Note absence of the corpus and tail of the pancreas (A; white star). The hepatic segment of the inferior vena cava (IVC) is absent. IVC is located on the left of the aorta and azygos continuation of the left IVC is present (A, B, C; black arrows). Cecum and ileocecal valve (arrow) is located in the left lower quadrant which is known as malrotation (D; white arrow). Renal arteries originate from at the same level as celiac truncus (E; black arrow). Also celiac truncus and superior mesentery artery have a shared origin (celiacomesenteric trunk) and it branches near the pancreas (F; white arrow).

\section{TRAUMA}

\section{Hematoma and Laceration}

Spleen is the most commonly injured solid organ after blunt trauma. Trauma may cause subcapsular hematoma, intraparenchymal hematoma and parenchymal laceration. On CT, hematomas appear as poorly defined areas of decreased attenuation and do not enhance. A contrast blush which is secondary to the extravasation of contrast media and persistence on delayed images is diagnosed as active hemorrhage. Lacerations usually appear linear or branching hypodensity usually with subcapsular hematomas (Figure 8). 3, 4, 5

\section{Splenosis}

Splenosis is an anomaly secondary to spleen cells seeding after splenic trauma or splenectomy. It is usually in the peritoneal cavity, often in the splenic fossa and left upper quadrant but occasionally it occurs extraperitoneal. ${ }^{8}$ Although both accessory spleen and splenosis are ectopic splenic tissues, their microscopic architecture, the blood supply and origins are differant. ${ }^{3}$ Spleen implants are usually multiple and different sizes. Splenosis is often asymptomatic and is detected by chance during imaging. Splenosis has similar imaging characteristics as a normal spleen (Figure 9). If normal spleen is not seen and there is a history of spleen trauma or splenectomy, splenosis becomes the most likely diagnosis. 


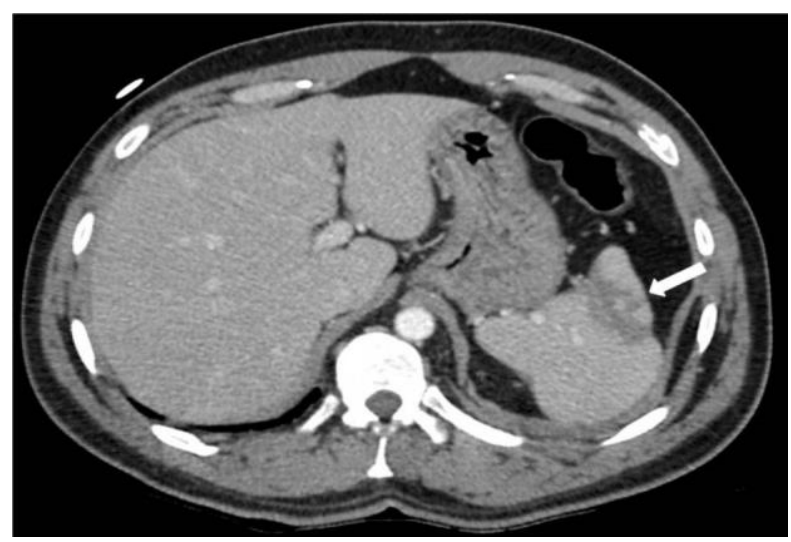

Figure 8: Twenty-eight-year-old man with splenic laceration. Axial contrast-enhanced CT demonstrates laceration (arrow) within the splenic parenchyma caused by penetrating trauma. It appears as branching hypodensity.

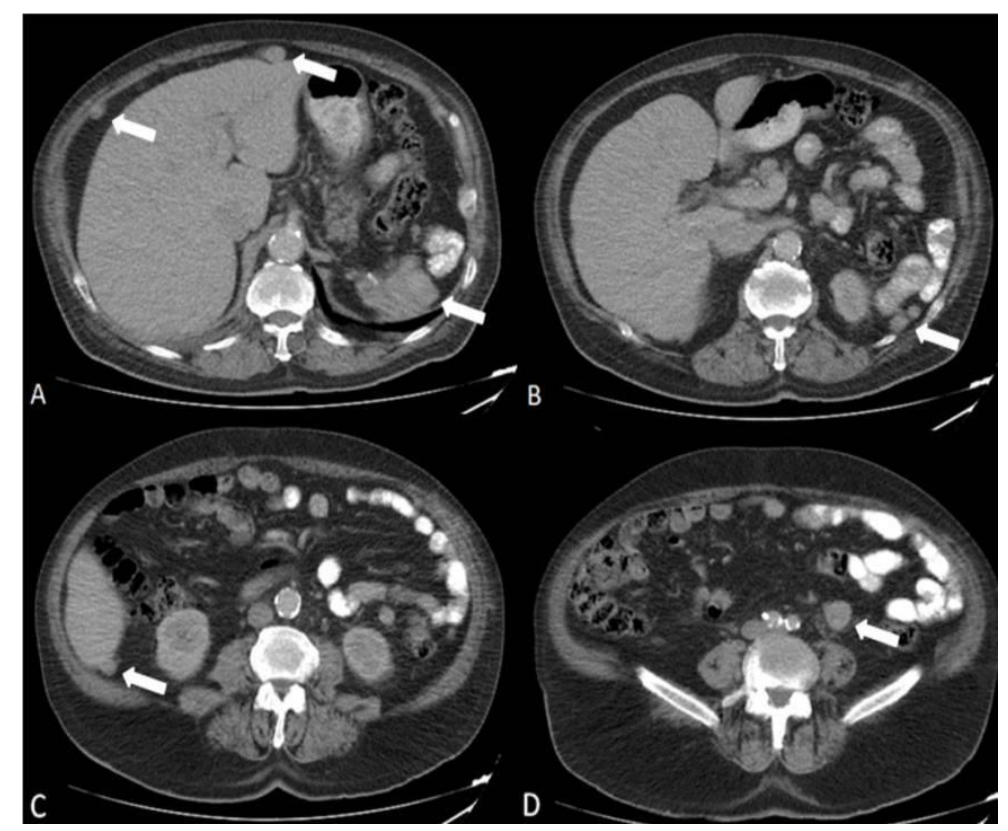

Figure 9: Splenosis. Normal spleen is absent. There are multiple round enhancing nodules in the left upper quadrant, anterior to the left and right liver (A, B; white arrows), inferior to the right liver (C; white arrow) and in the left lower quandrant (D; white arrow) on contrast enhanced CT.

\section{INFECTIOUS/INFLAMMATORY DISEASES}

\section{Pyogenic Abscesses}

Pyogenic abscesses are the collection of localized pus with high mortality rates. Escherichia coli and Salmonella are the most frequently encountered pathogens. They are most commonly caused by hematogenous spread of infection. Endocarditis is the most commonly associated primary site. ${ }^{9}$ Also $15 \%$ of cases occur after trauma and $10 \%$ are develop after preexisting splenic infarction. ${ }^{10}$ They are usually unilocular but rarely multifocal. On US, it appears ill-defined hypoechoic masses. Gas is seen as high echogenicity associated with distal dirty shadowing. CT is the most reliable tecnique. A solitary abscess is a well-defined. It has density values ranging from 20 to $40 \mathrm{HU}$. The presence of gas is diagnostic for pyogenic abscesses, but it is not seen in the majority of cases. Abscesses are hypointense on T1-weighted images (T1W) and a moderate to high signal intensity on $\mathrm{T} 2 \mathrm{~W}$ with smooth or irregular margins. Peripheral contrast enhancement may be seen both on CT and MRI when the capsule has developed. There can be septations of various thickness from 1 to $10 \mathrm{~mm} .{ }^{9}$, 10 


\section{Hydatid Cyst}

Hydatid cysts are usually caused by Echinococcus granulosus and commonly seen in endemic areas. Splenic involvement is rare, occuring less than in $2 \%$. Concurrent liver cysts are frequently seen in most cases of the splenic hydatid diseases. Systemic dissemination and intraperitoneal spread from a ruptured liver cyst are two main reasons of splenic involvement. Hydatid cysts are usually sharply demarcated, round or oval lesions. They can be unilocular or have a multilocular appearance secondary to small peripheral daughter cysts (Figure 10). They have attenuation equal to that of water. However, the lesion may appear at a higher attenuation due to intracystic debris, protein, or inflammation. They are hypointense on $\mathrm{T} 1 \mathrm{~W}$ and hyperintense on $\mathrm{T} 2 \mathrm{~W}$. Typically there is no rim enhancement. ${ }^{7}$ Ringlike calcifications may be seen in the periphery mostly in the dead cysts. ${ }^{9}$

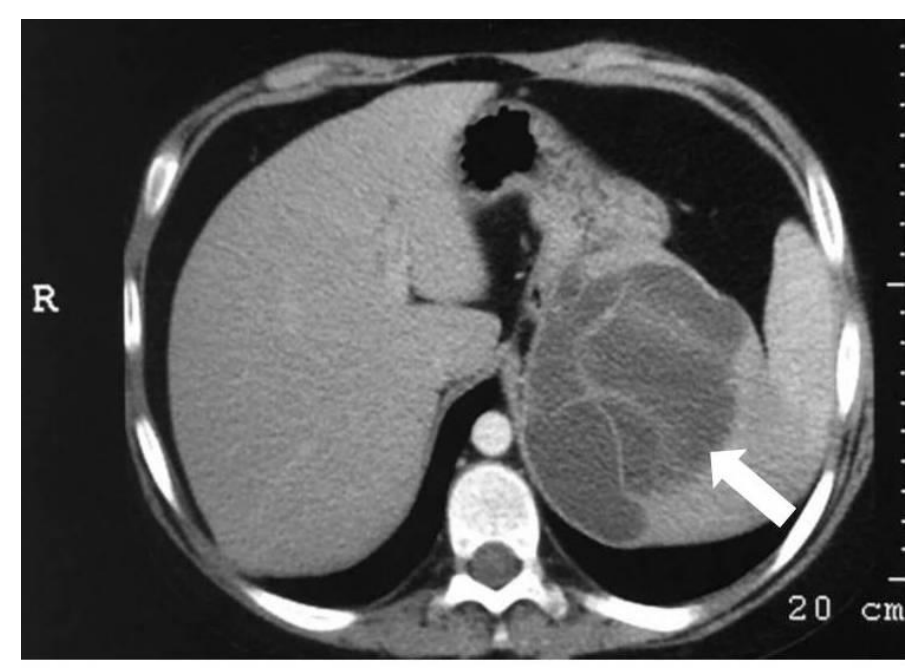

Figure 10: Fourteen-year-old boy with splenic cyst hydatid. Axial contrast-enhanced CT scan demonstrates replacement of the entire spleen by a cyst which shows linear tortuous structures within suggestive of ruptured endocyst.

\section{Fungal Abscesses}

Fungal abscesses usually occur in immunocompromised patients. Candida albicans is the most common infecting organism. Microabscesses are typically larger and smaller than $2 \mathrm{~cm}$. On US, the 'wheel in wheel' pattern is observed in early disease due to peripheral hypoechoic region, internal echogenic region and central hypoechoic nidus. Due to the central hyperechoic inflammatory core surrounded by hypoechoic fibrotic tissue, the 'target' or 'bull's-eye' appearance is seen when patients return the neutrophil count to normal. The most common finding on $\mathrm{CT}$ is multiple round hypodense lesions or calcifications. MRI is superior to CT for the detection and characterization of fungal microprocesses. They appear as hypointense on $\mathrm{T} 1 \mathrm{~W}$ and hyperintense on $\mathrm{T} 2 \mathrm{~W}$ with peripheral ring enhancement on gadolinium-enhanced images (Figure 11). 3, 6, 10 


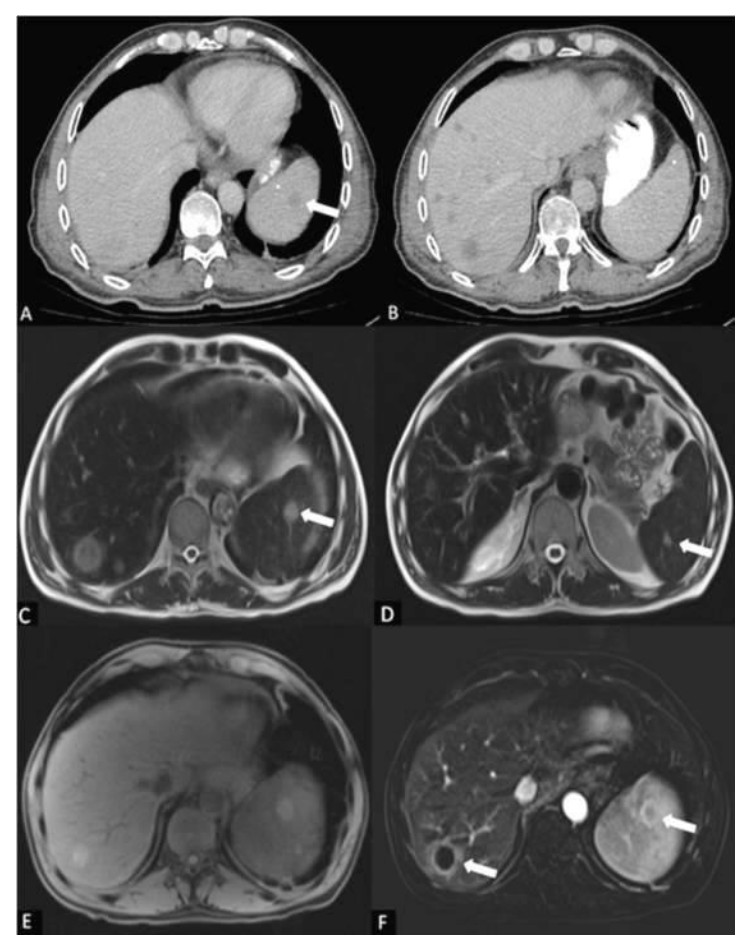

Figure 11: Forty-eight -year-old man with hepatosplenic candidiasis in a patient with aplastic anemia. Axial contrast-enhanced CT shows (A) hypodense fungal abscess (white arrow) and (B) concurrent lesions in the liver. (C, D) Axial T2W shows round hypointense fungal abscesses within the spleen (C, D; white arrows) and liver. (E) Lesions are mild hyperintense on T1W and (F) postcontrast MRI shows perypheral ring enhancement (white arrows).

\section{Tuberculosis}

There are two main types of spleen tuberculosis: micronodular (milier) and macronodular. Micronodular form is the most common form that usually appears as hyperechoic splenomegaly on US. Miliary nodules may appear as hypodense on CT. Calcifications may occur in late stage disease. The macronodular form is extremely rare, and can be single or multiple. CT findings are nonspecific and variable. CT shows a non-calcified low-density lesion or a calcified high-density lesion with or without contrast. Both micronodular and macronodular tuberculous lesion are hypointense on T1W and hyperintense on $\mathrm{T} 2 \mathrm{~W}$, yet these MR findings are usually nonspecific (Figure 12). ${ }^{9}, 10$, 11,12

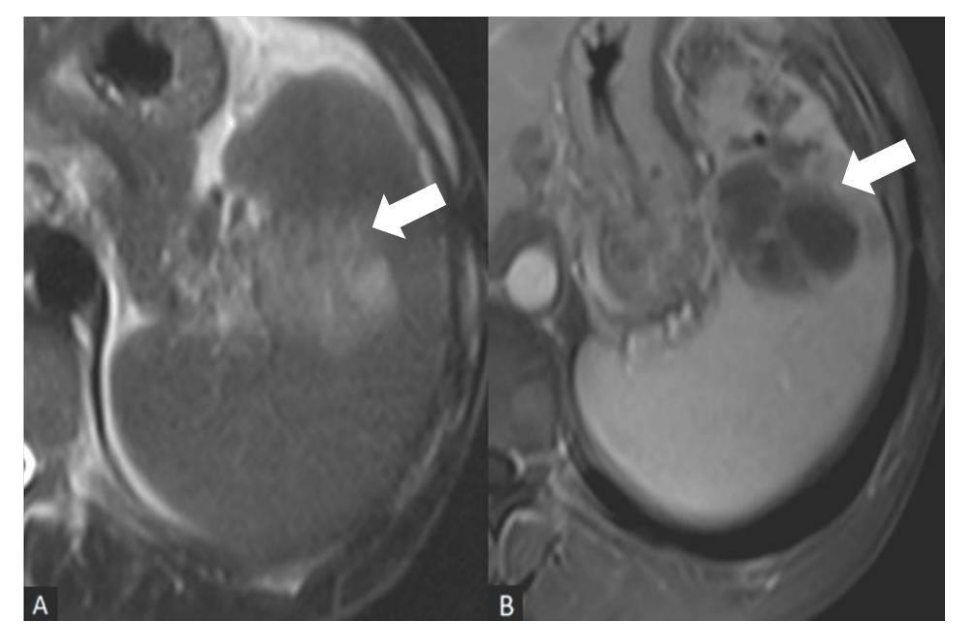

Figure 12: Splenic tuberculosis. (A) Axial fat-suppressed T2W demonstrates hyperintenselesion in the spleen. (B) On postcontrast MRI, no enhancement is seen. 


\section{Sarcoidosis}

Sarcoidosis is a multisystem granulomatous disease that is characterized by noncaseating granuloma on histology. The lung, mediastinal and hilar lymph nodes are primarily affected. Splenic involvement is up to $59 \%$ of cases, although isolated splenic disease is quite rare. ${ }^{7,} 11$ Splenomegaly with associated lymphadenopathy and hepatomegaly are the most common appearance both on US and CT. ${ }^{12}$ Less commonly, there is a nodular form. Nodules are multiple, diffusely scattered, $1 \mathrm{~mm}$ to $3 \mathrm{~cm}$ lesions. They are hypoechoic on US and hypodense on CT. On MRI, nodules are hypointense on all MRI sequences, and this is most conspicuous on fat-suppressed T2W. Nodules are hypovascular with only minimal or delayed enhancement (Figure 13).

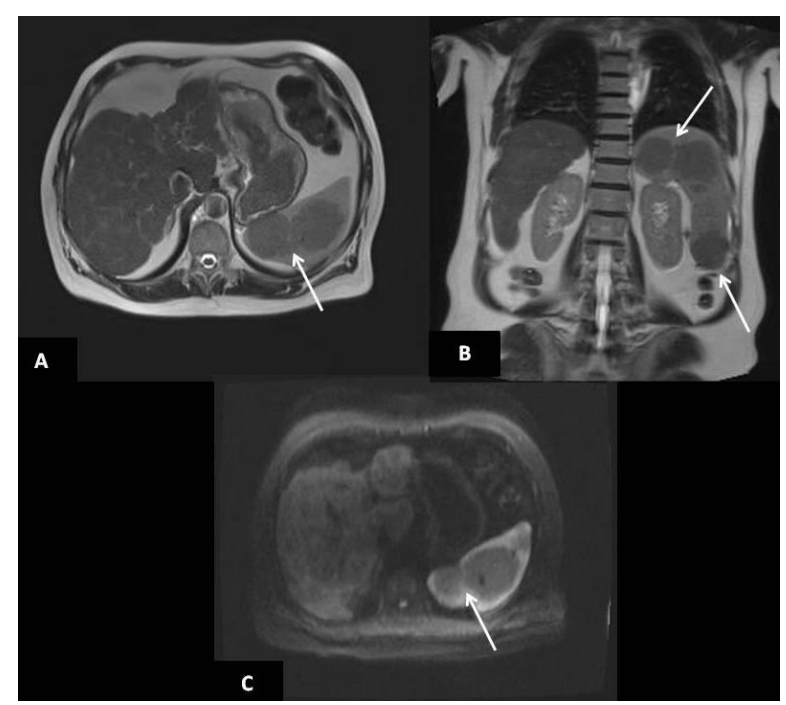

Figure 13: Fourty-eight-year old woman with sarcoidosis. Axial (A) and coronal (B) T2W MR images show ill-defined mild hypointense lesions in the spleen (white arrows). In axial $b=800 \mathrm{~mm}^{2} / \mathrm{s}$ diffusion weighted image $(\mathrm{C})$, there is no pathological diffusion restriction.

\section{Histoplasmosis}

Histoplasmosis is caused by Histoplasma capsulatum and usually seen in endemic areas. It is most commonly seen in immunocompromised patients. MRI demonstrates scattered hypointense lesions on both T1W and T2W. Multiple punctate calcifications may be seen in old granulomas (Figure 14). ${ }^{13}$

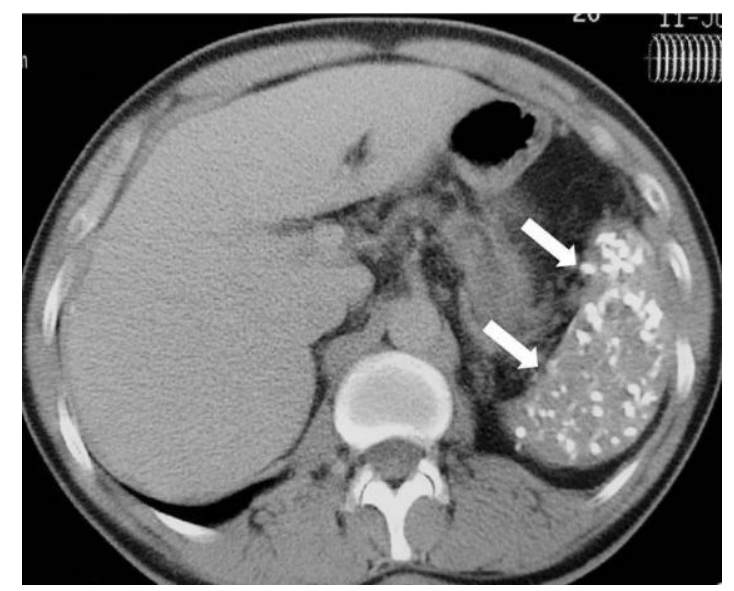

Figure 14: Histoplasmosis. On axial non-enhanced CT, multiple calcifications are demonstrated throughout the spleen as sequela of histoplasmosis. 


\section{Infarction}

Splenic infarcts are mostly caused by tromboembolic process, occuring in any type of hemolytic anemia, endocartitis, atrial fibrillation, portal hypertension, or vascular collagen diseases. ${ }^{13}$ Typical but rare appearance of infarction is a peripheral wedge-shaped hypoattenation lesion that becomes more evident after intravenous contrast administration. In less frequent cases, infarct areas may appear as heterogeneous, poorly marginated and massive hypoattenuating lesions. In the hyperacute phase, a hemorrhagic infarct may cause a mottled pattern that appears hyperintense on $\mathrm{T} 1 \mathrm{~W}$. In the acute and subacute phases, infarcts become more focal and better demarcated. In the chronic phase, they have low signal intensity on T1W and high signal intensity on $\mathrm{T} 2 \mathrm{~W}$ with/without fibrous contraction (Figure 15). ${ }^{10,12}$

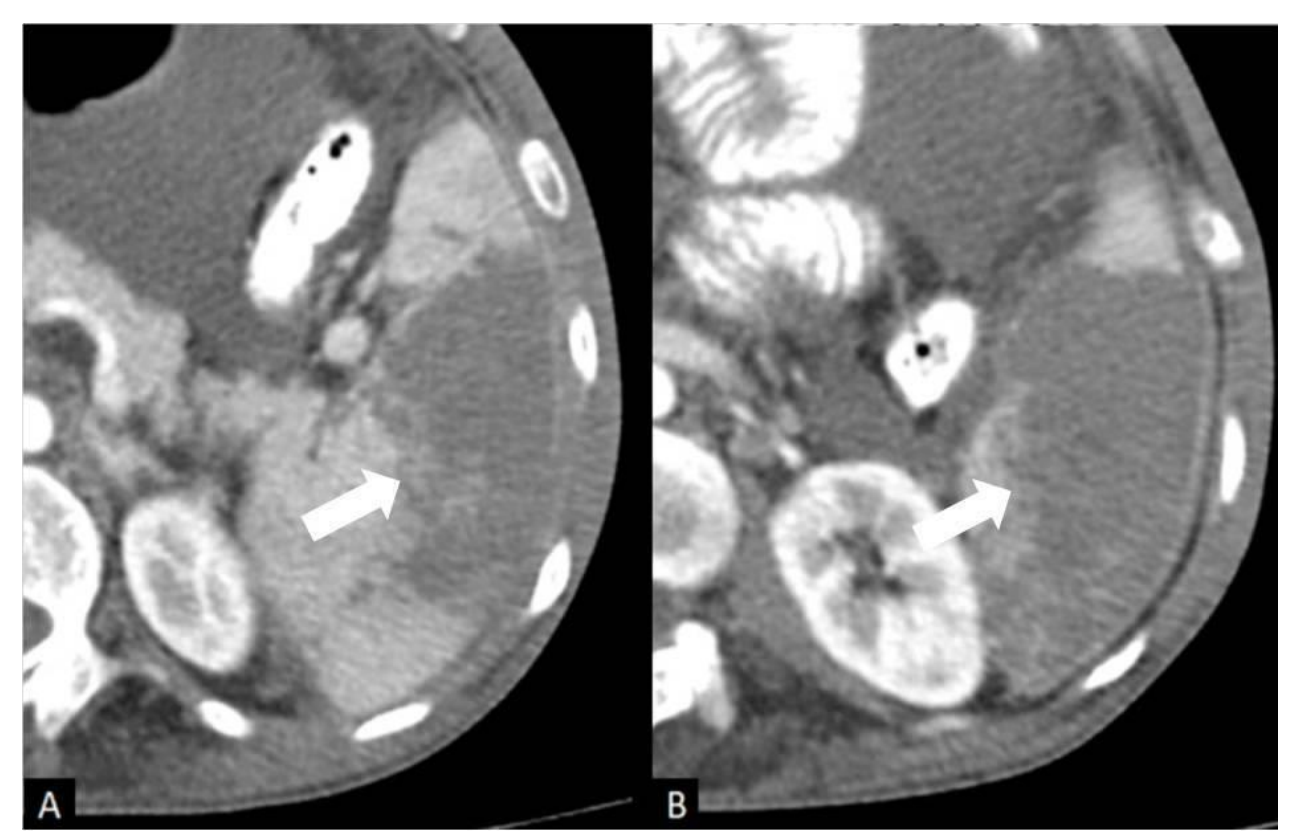

Figure 15: Twenty-nine-year-old man with splenic infarction. Axial contrast-enhanced CT shows welldemarcated wedge-shaped hypoattenuating lesion corresponding to infarction.

\section{Sclerosing Angiomatoid Nodular Transformation}

Sclerosing angiomatoid nodular transformation (SANT) is a rare benign vascular splenic lesion consisting of multiple angiomatoid nodules surrounded by dense fibrous stroma that form a central scar. Most of the cases are asymptomatic and detected incidentally. SANT presents as a solitary, lobulated, well-circumscribed nodule that is distinct from the surrounding splenic parenchyma. On US, it has an isoechoic appearance with hypoechoic rim and increased vascularity on color Doppler. On noncontrast CT, it is slightly hypodense relative to normal spleen. The mass is T2 hyperintense at the periphery and $\mathrm{T} 2$ hypointense radiating bands corresponding with areas of fibrosis. On postcontrast images, on both $\mathrm{CT}$ and MRI the mass shows peripheral enhancement during arterial and venous phase and delayed enhancement in a radiating pattern at the central area due to fibrous tissue. This appearance has been described as spoke-wheel pattern (Figure 16). ${ }^{10,11,12,13}$ 


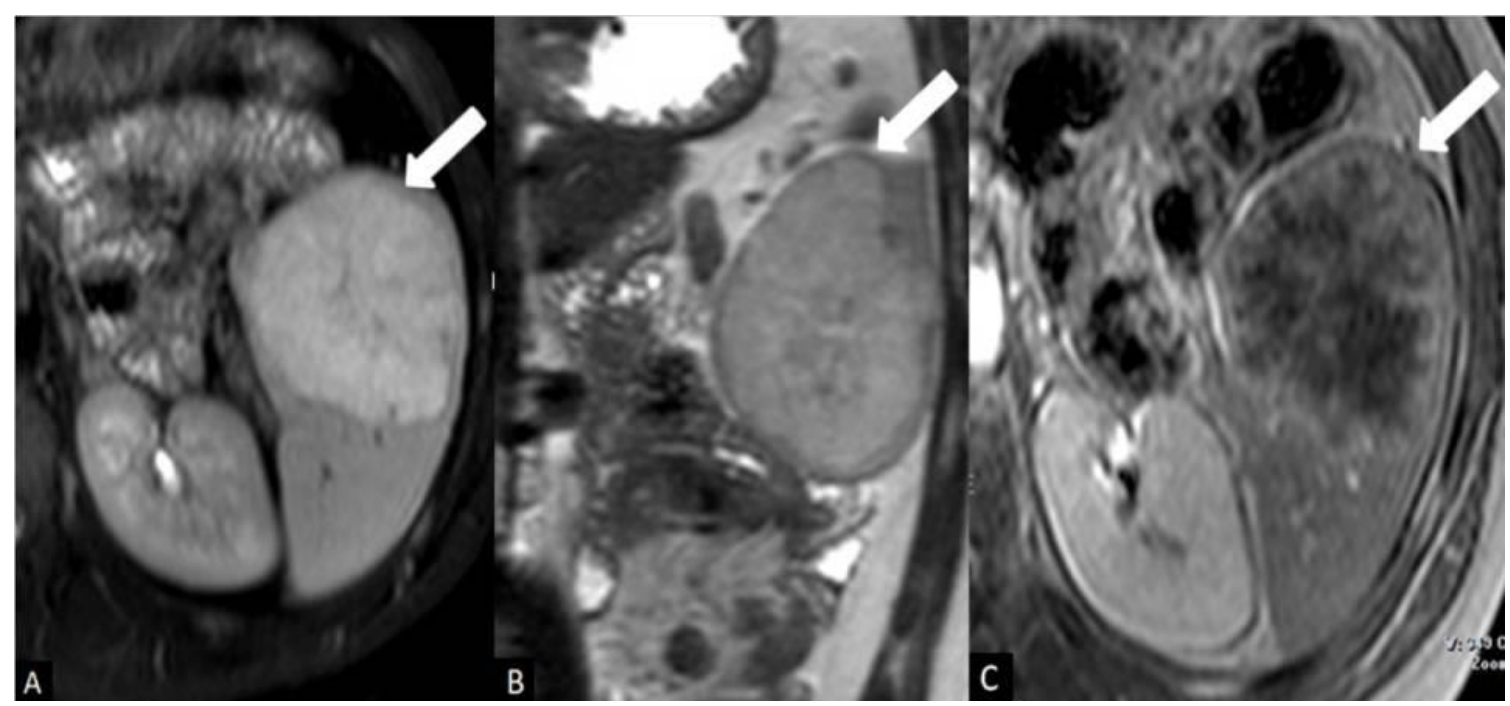

Figure 16: Sclerosing angiomatoid nodular transformation. (A) Axial fat-suppressed T2W and (B) coronal $\mathrm{T} 2 \mathrm{~W}$ show heterogeneous hyperintense mass with hypointense central scar (arrows). (C) Postcontrast arterial phase T1 images show perypheral enhancement with hyperintense radiations towards center of lesion which is similar to 'spoke-wheel pattern' (arrow).

\section{Myelofibrosis}

Myelofibrosis is a myeloproliferative disorder that may be primary or secondary and usually affects adults. On imaging, hepatosplenomegaly, osteosclerosis and lymphadenopathy may be seen. Splenomegaly is the most common finding, and it is usually massive (Figure 17). Associated splenic infarction and extramedullary hematopoesis may ocur. $^{14}$

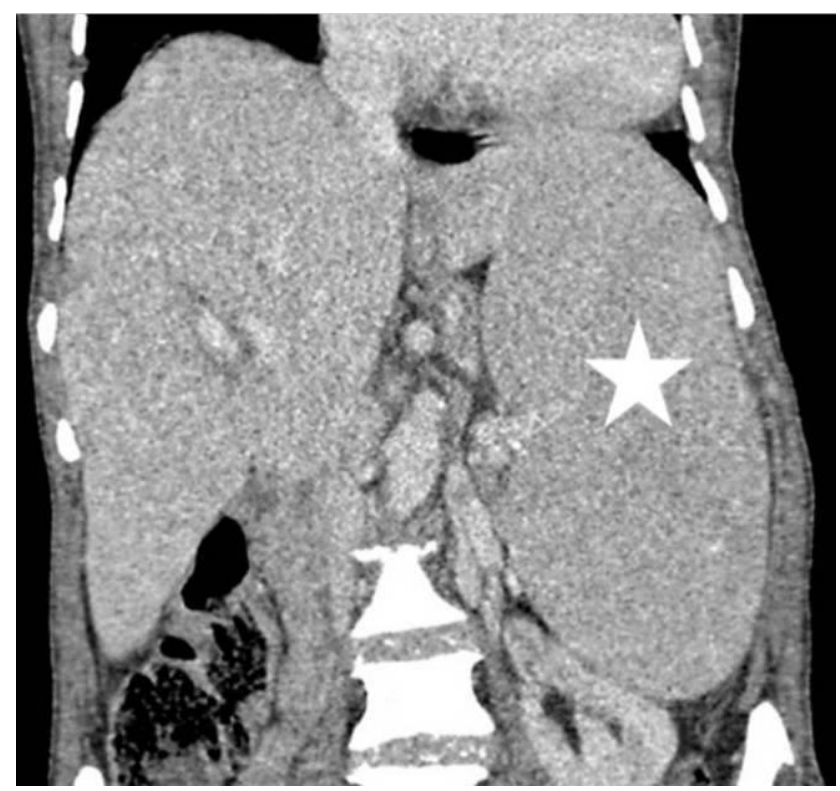

Figure 17: Seventy-seven-year-old woman with myelofibrosis. Coronal contrast-enhanced CT demonstrates massive splenomegaly in a patient with myelofibrosis.

\section{BENIGN AND MALIGNANT TUMORS}

\section{Cysts}

Cysts are the most frequent focal splenic lesions. They can be classified as primary (true cyst) or secondary (false cyst). True cysts have an epithelial lining and are either parasitic or nonparasitic (epidermoid). False cysts are lack an epithelial lining, and may result from trauma, infarction or infection. False cysts are much more common. They have mural calcifications in the wall in 50\% of cases and they are usually located close to the 
splenic capsule. ${ }^{5}$ In imaging, cysts are typically seen as thin-walled, round-shaped, well-confined, and non-enhancing lesions. On MRI, they are hypointense on T1W and strongly hyperintense on $\mathrm{T} 2 \mathrm{~W}$. Increased density on CT or signal intensity on $\mathrm{T} 1 \mathrm{~W}$ may correspond to hemorrhagic or proteinaceous content (Figure 18). Differentiating a benign cystic lesion from a malignant lesion is important. Absence of wall-thickening or adjacent solid contrast-enhancing component is in favour of benign lesions. ${ }^{6}$

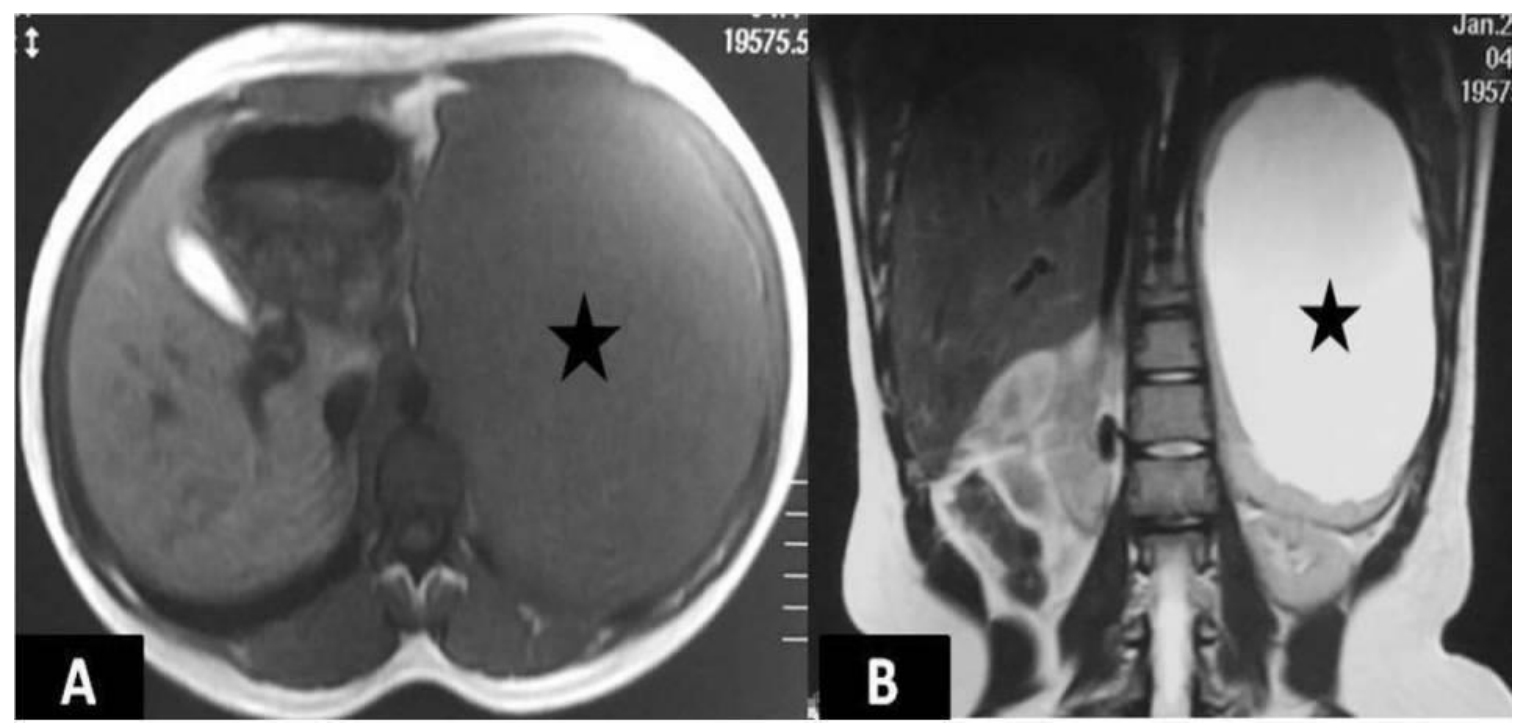

Figure 18: Sixteen-year-old girl. (A) Axial precontrast T1W MR, and (B) coronal T2W images demonstrate the large cystic lesion (black stars) within the spleen (Pathology specimen result: Pseudocyst).

\section{Hemangioma}

Hemangiomas are the most common benign primary neoplasm of the spleen. They form by proliferation of vascular channels filled with slowflowing blood. According to the size of these channels, they are characterized as capillary and cavernous types. Cavernous hemangiomas are more common. Solitary hemangiomas are usually seen, but occasionally they can be multiple. Multiple splenic hemangiomas can be associated with angiomatosis syndromes such as KasabachMerritt syndrome or Klippel-Trenaunay-Weber syndrome. Most hemangiomas are less than $2 \mathrm{~cm}$ in diameter with well-defined borders and homogeneous appearance. On US, capillary hemangiomas are typically hyperechoic, however cavernous hemangiomas can be hypoechoic [6]. Most hemangiomas are hypodense on unenhanced CT. After contrast administration, cavernous hemangiomas show early peripheral enhancement extending toward the centre on portal-venous and delayed phases. Although smaller hemangiomas may show homogeneous enhancement (Figure 19). Capillary hemangiomas enhance homogeneously. On MRI, hemangiomas are hypo- or isointense on $\mathrm{T} 1 \mathrm{~W}$ and hyperintense on $\mathrm{T} 2 \mathrm{~W}$. The signal intensity can vary due to presence of hemorrhage and proteinaceous content that appear high signal intensity on $\mathrm{T} 1 \mathrm{~W}$. The enhancement pattern on MRI is similar as on CT. ${ }^{10,11,12}$

\section{Hamartoma}

Splenic hamartomas are rare benign tumors that consist of disorganized stroma and vascular channels. Hamartomas are usually well-defined, rounded, solid lesions but may contain cystic or necrotic components. They are mostly seen solitary, although occasionally can be multiple. On US, hamartomas are typically homogeneous hyperechoic lesions. Color Doppler US demonstrates increased blood flow. They usually appear iso- or hypodence on noncontrast CT and occasionally may contain calcification or fatty components. On MRI, they are isointense to splenic parenchyma on T1W and heterogeneously hyperintense on T2W. After contrast administration, there is usually diffuse heterogeneous early enhancement on both CT and MRI, which is useful to differentiate hamartomas from hemangiomas. On delayed images, prolonged hyperenhancement may be seen and help distinguish hamartoma from lymphoma. ${ }^{9}, 10,12,13$ 


\section{Lymphangioma}

Lymphangiomas are rare benign tumors usually seen in children. They are composed of malformations of the lymphatic system. They are usually located close to the splenic capsule and may be isolated or may be part of a systemic lymphangiomatosis syndrome. $^{10}$ Cystic lymphangiomas which are the most common type, typically appear multilocular, thin-walled, well- circumscribed cysts containing lymph-like clear water. ${ }^{13}$ CT demonstrates a nonenhancing low attenuated lesion. Enhancement of the septa and tiny curvilinear peripheral calcifications may be detected. On MRI, multilocular lesions are homogeneously hyperintense on T2W and hypointense on $\mathrm{T} 1 \mathrm{~W}$ with hypointense fibrous septations. There may be high signal intensity on T1W due to proteinaceous or hemorrhagic content (Figure 20).

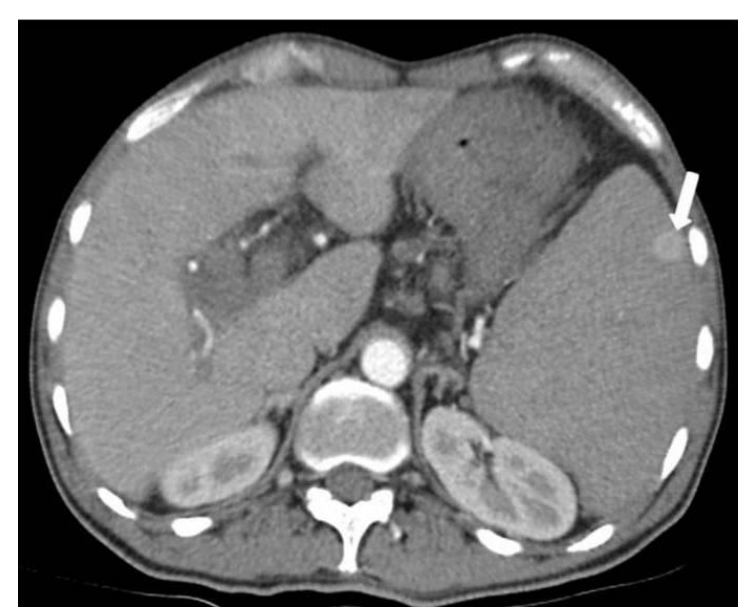

Figure 19: Hemangioma. Axial contrast-enhanced CT shows diffuse enhancement in late arterial phase postcontrast images.

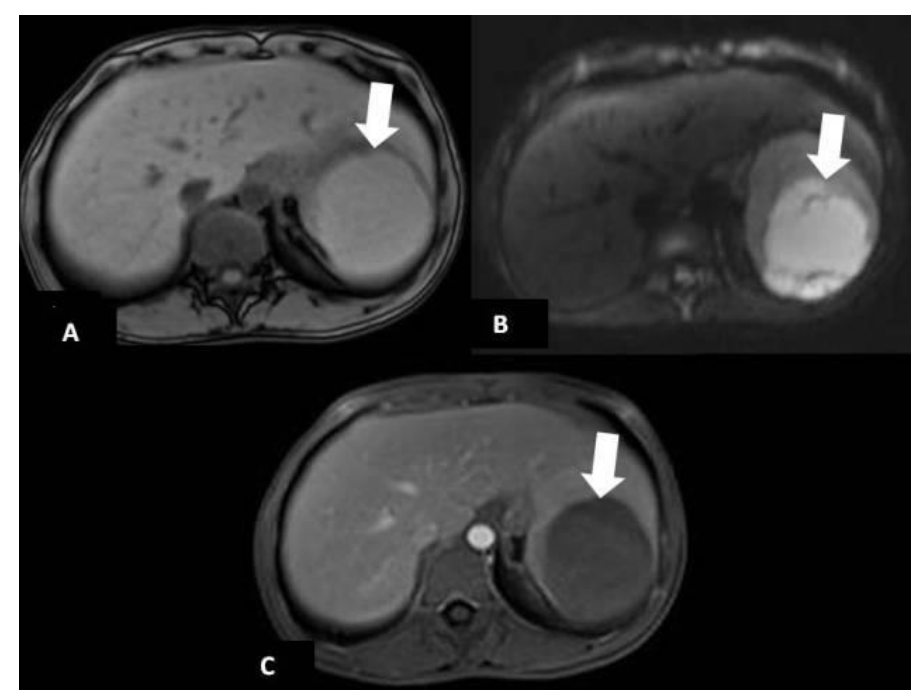

Figure 20: Splenic lymphangioma. (A) Axial fat-supressed T1W image shows a hyperintense cystic mass (arrow). (B) On axial fat-supresssed contrast-enhanced T1W image, pathological contrast-enhancement is not observed (arrow). (C) Axial fat-supressed T2W image shows a hyperintense cystic mass with septae (arrow).

\section{Lymphoma}

The most common malignant tumor of the spleen is lymphoma that can be either primary or secondary. Primary involvement is quite rare, most of which are Non-Hodgkin lymphomas (5). Secondary involvement of the spleen occurs as a part of systemic disease. Splenic lymphoma can present as splenomegaly without a discrete mass $(80 \%)$, a solitary mass, multiple focal nodular lesions or miliary lesions. Necrosis may cause a cystic appearance. Calcifications are rare, probably they occur secondary to treatment. Nodular lesions 
or focal masses usually appear hypoechoic on US and hypodense on CT. Lymphomas are isointense to splenic parenchyma on T1W and T2W, although they may be hypointense on $\mathrm{T} 2 \mathrm{~W}$. Lesions are best detected after contrast administration as hypoenhancing lesion than normal splenic parenchyma (Figure 21). ${ }^{11,13,15}$

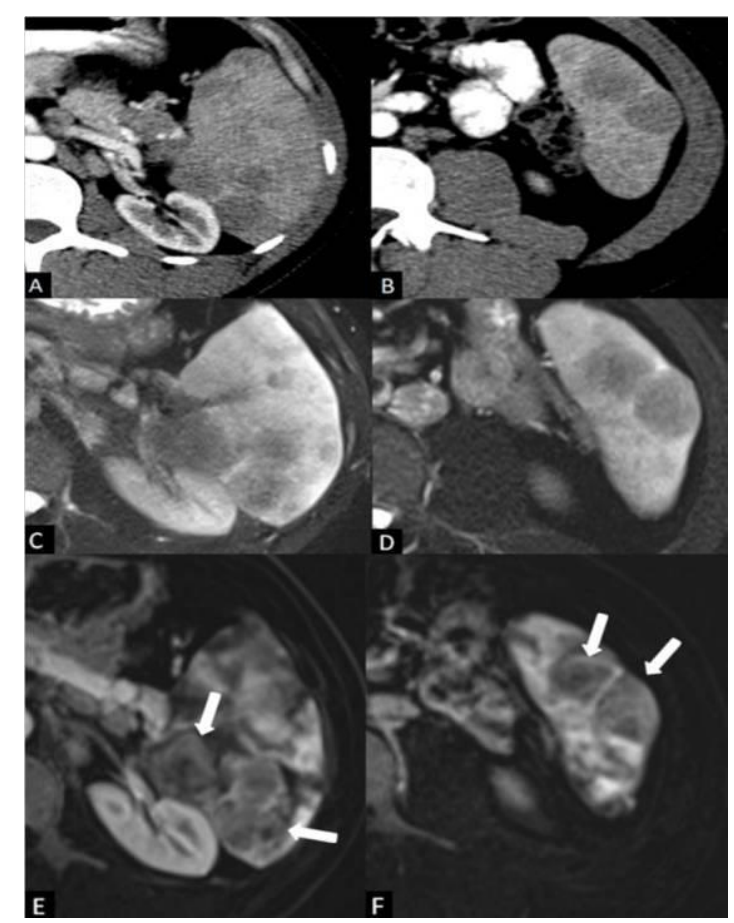

Figure 21: 39-year-old man with Non-Hodgkin lymphoma. (A, B) Axial non-enhanced CT shows multiple round hypodense lesions throughout the spleen. (C, D) On axial fatsuppressed T2W, lymphomatous lesions are hypointense. (E, F) Lymphomatous lesion are hypovascular with lower signal intensity on postcontrast MRI (arrows).

\section{Leukemia}

Imaging findings of leukemia include hepatomegaly, lymphadenopathy, splenomegaly and focal nodular lesions in the liver and spleen [12]. Splenic involvement is more common with chronic forms of the disease. Massive splenomegaly may cause spontaneous splenic rupture in $25 \%$ of patients [12]. Metastasis The spleen is a rare site for metastatic disease with only $7 \%$ occurence [11]. Metastatic lesions are usually secondary to hematogeneous spread in malignant melanoma, gynecologic malignancies, breast, lung and stomach cancers. Solitary or multiple lesions with variable sizes usually demonstrate hypoechoic appearance on US. Cystic splenic metastasis are most commonly seen in melanoma. On CT, splenic metastasis are hypodense with homogeneous or heterogeneous enhancement. Calcifications may be noted if the primary tumor is mucinous adenocarcinoma. MRI demonstrates hypo- to isointensity on T1-WI and mild hyperintensity on T2-WI. Melanoma metastasis can be hyperintense on T1-WI due to hemorrhage or the intrinsic paramagnetic proporties of melanin (Figure 22). ${ }^{11}$, $12,14,15$ 


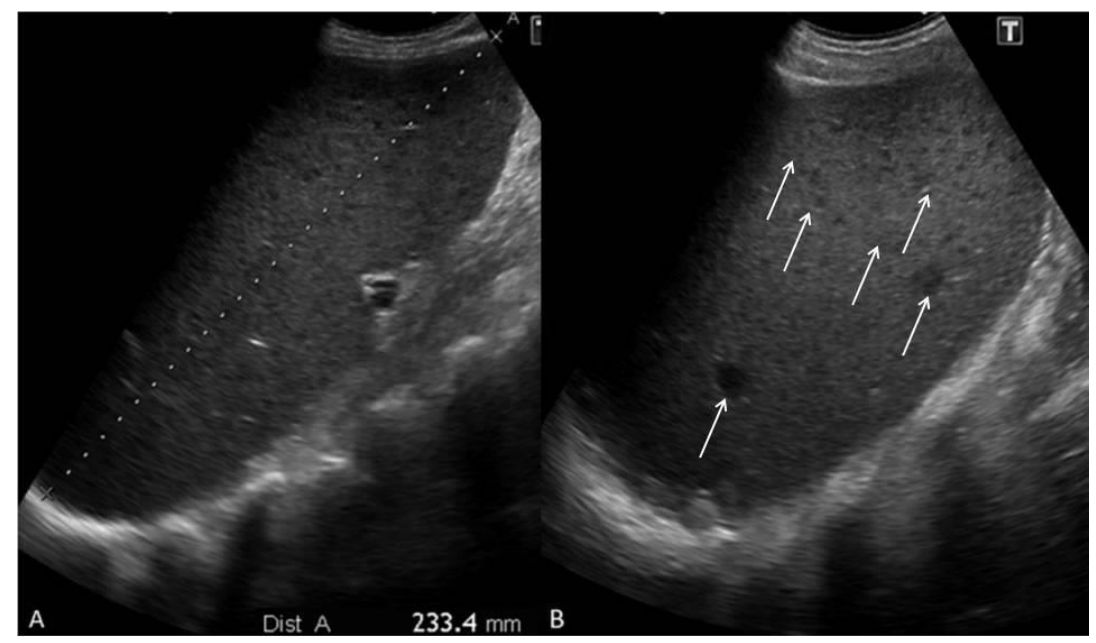

Figure 22: Seventy-five-year-old man with chronic lymphocytic leukemia. US shows massive splenomegaly (A) and multiple rounded hypoechoic lesions (B) in the spleen (arrows).

\section{OTHERS}

\section{Splenomegaly}

Splenomegaly is a common manifestation in many diseases. This may result most frequently result from portal hypertension, often associated with liver cirrhosis. Other causes of splenomegaly may include hematological disorders, neoplastic diseases and inflamatory diseases. Although the size of spleen varies, the upper limit defined as 15 $\mathrm{cm}$ length, $10 \mathrm{~cm}$ width and $6 \mathrm{~cm}$ depth. ${ }^{5}$

\section{CONCLUSION}

Focal and diffuse lesions affecting the spleen are rare and are often detected incidentally during radiological examinations. The knowledge of imaging findings and differential diagnosis of splenic lesions help radiologists in daily routine.

Conflict of interest: The authors report no conflict of interest.

This paper has been presented as an electronic poster at the European Congress of Radiology 2018.

\section{REFERENCES}

1. Kuint RC, Daneman A, Navarro OM, Oates A. Sonographic Bands of Hypoechogenicity in the Spleen in Children: Zebra Spleen. AJR Am J Roentgenol. 2016; 207: 648-52.

2. Gayer G, Hertz M, Strauss S, Zissin R. Congenital anomalies of the spleen. Semin Ultrasound CT MR 2006; 27: 358-69.

3. Yildiz AE, Ariyurek MO, Karcaaltincaba M. Splenic Anomalies Shape, Size and Location: Pictoral Essay. 2013 Apr 21;2013:321810. doi: $10.1155 / 2013 / 321810$.
4. Kim SW, Shin HC, Kim IY, Bae S-B, Park JM. Duplication of the spleen with a short pancreas. $\mathrm{Br}$ J Radiol 2009; 82: 42-3.

5. Le D, Schierloh U, Van Nieuwenhuyse JP, Nchimi A. J Belg Soc Radiol. 2016 Sep 21;100: 79. doi: 10.5334/jbr-btr.1187.

6. Vancauwenberghe T, Snoeckx A, Vanbecvoort D, Dymarkowski S, Vanhoenacker FM. Imaging of the spleen: what the clinician needs to know. Singapore Med J 2015; 56: 133-44.

7. Omeri AK, Matsumoto S, Kiyonaga M, Takaji R, Yamada Y, Y Ando, et al. Fusion anomaly of the pancreatic tail and spleen: a case report. J Med Case Rep. 2017 Aug 27;11(1):238. doi: 10.1186/s13256-017-1391-3.

8. Felice M, Tourojman M, Rogers C. Right retroperitoneal splenosis presenting as an adrenal mass. Urol Case Rep 2017: 16; 44-5.

9. Warshauer DM, Lee Hall H. Solitary Splenic Lesions. Seminars in Ultrasound, CT and MRI 2006: $27: 370-88$.

10. Kamaya A, Weinstein S, Desser TS. Multiple Lesions of the Spleen: Differential Diagnosis of Cystic and Solid Lesions. Seminars in Ultrasound, CT and MRI. 2006; 27: 389-403.

11. Thut D, Smolinski S, Morrow M, McCarthy S, Alsina J, Kreychman A, et al. A diagnostic approach to splenic lesions. Applied Radiology. 2017; 2: 7-22.

12. Bean MJ, Horton KM, Fishman EK. Concurrent Focal Hepatic and Splenic Lesions: A Pictoral Guide to Differential Diagnosis. J Comput Assist Tomogr 2004; 28: 605-12. 
13. Palas J, Matos AP, Ramalho M. The Spleen Revisited: An Overview on Magnetic Resonance Imaging. Radiol Res Pract 2013; 2013: 219-297.

14. Saboo SS, Krajewski KM, O'Regan KN, Giardino A, Brown JR, Ramaiya N, et al. Spleen in haematological malignancies: spectrum of imaging findings. Br J Radiol. 2012; 85: 81-92.
15. Boehnke MW, Watterson CT, Connolly SA, Perez-Atayde AR, Weldon CB, Callahan MJ. Imaging features of pathologically proven pediatric splenic masses. Pediatr Radiol. 2020 Jun 3. doi: $10.1007 / \mathrm{s} 00247-020-04692-3$. Online ahead of print. 